\title{
Comparative Effect of Interactive Multimedia to Text-Based Content for Software Application Courses
}

Edwin Mwosa Kivuti, Jommo Kenyatta University of Agriculture and Technology, Kenya

\begin{abstract}
This study evaluated the comparative effect of interactive multimedia to text-based content on learners taking a software application course. One hundred eleven participants took part in the study. The researcher employed the use of web analytics and online surveys to capture data. The study showed that there was a significant difference in the learner preference for either type of content. An exploratory study on the learner preference of specific interactive multimedia features showed that learners preferred the video presentation and the VDI rather than the other features. The study also evaluated the comparative effect of the two content types on learner comprehension. For instance, where learners made use of interactive multimedia, they performed significantly better than instances where learners made use of text-based content. These results suggest that use of interactive multimedia can lead to better comprehension and participation than text-based content in self-paced software application courses.
\end{abstract}

\section{KEYWORDS}

Comprehension Rate, KTDA (Kenya Tea Development Agency), Mayer's Theory, Moodle LMS, Preference Rate, SAP, Self-Paced Courses, VDI (Virtual Desktop Infrastructure), Web Analytics

\section{INTRODUCTION}

Computer-assisted learning has gone a long way toward bridging the digital divide. People from distant parts of the world are now able to access up-to-date educational content through e-learning. One mode of developing self-paced e-learning content is through interactive multimedia. Interactive multimedia content can be described as online instruction that combines multimedia features with activities that help learners to apply their knowledge and receive feedback from the content (Mayer, 2009). Interactive multimedia course content consists of "print, sound, visuals, animation, movies, interactivity, non-linear navigation, together with encyclopedic references and a virtual environment" (Taub, 2019). The term "interactive multimedia" has also been described as a system where multiple media may have an effect on people through interactive behavior (Deliyannis, 2012). Therefore, interactive multimedia includes not only video but also interactive features meant to aid the learner. For the purposes of this study, text-based content is defined as instructional content that only includes text and still images, and which is delivered in either soft copy format. A software application course is defined as a training program meant to educate learners on how to use a particular software application.

DOI: 10.4018/IJICTE.20211001.oa16

This article published as an Open Access article distributed under the terms of the Creative Commons Attribution License (http://creativecommons.org/licenses/by/4.0/) which permits unrestricted use, distribution, and production in any medium, provided the author of the original work and original publication source are properly credited. 


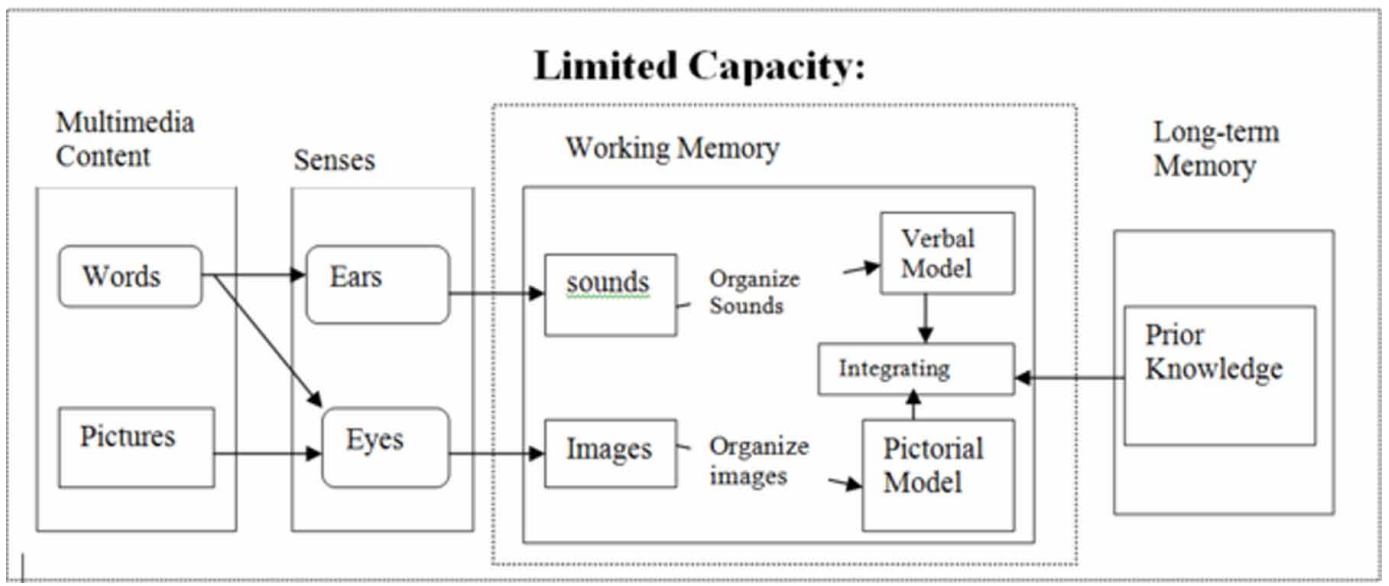

This study evaluates the effects of interactive multimedia in comparison to text-based content when used in a software application course. As described in the subsequent section, previous research in this area has resulted in different outcomes. This study uses novel interactive technologies, for example the Virtual Desktop Infrastructure (VDI), so as to evaluate the effects of these technologies on the learner.

\section{Motivation And Contribution}

As confirmed by Afify (2018), researchers who have investigated the influence of multimedia content on learners have drawn different conclusions. Stice, Stice, and Albrecht (2015) showed that introductory accounting learners who read text-based content outperform those who learn using multimedia content. Werbach (2016) exemplifies a case where an interactive multimedia platform that took 4 years to be developed led to low student performance. Some researchers argue that the use of multimedia content results in cognitive overload (Coward, Crooks, Flores \& Dao, 2012). As shown below multimedia content may result in cognitive overload due to the limited capacity of the working memory.

Other studies have shown that there's no significant advantage in using multimedia content. Hassan (2016) concluded that multimedia content improves learning. The learning content that their participants went through was based on phases of the moon. Kayalar and Kayalar (2017) concluded that auditory learners studying languages would be at an advantage if they use multimedia-based content. In a separate study, the comparative effect of multimedia content to static content was tested on pharmacology and physiology students (Daly, Bulloch, Ma \& Aidulis, 2016). When interviewed, most of the students in that study showed preference for multimedia content, but the actual test results did not show a statistical difference.

Some researchers have concluded that multimedia-based content is better than traditional learning content (Hassan, 2016; Kayalar \& Kayalar, 2017). In their study, Ibrahem and Alamro (2020) suggest that animated content has a greater effect on male learners while static content has a greater effect on female learners. One key difference in these studies is the subject that the learners were taking. This study extends other studies by investigating the effect of interactive multimedia on self-paced learners taking software-training courses

In a literature review of multimedia-learning research, Mutlu-Bayraktar, Cosgun and Altan (2019), showed that there's limited research on working adults and elementary level learners. The researchers recommended further research on the effect of multimedia on these two groups. In addition, Pastore, 
Briskin, and Asino (2016) argue that researchers have not taken much interest in investigating the effect of static content delivered through computers to adult learners. It is for this reason that the participants in this study were in-service, adult learners.

One major factor in learning is the learning environment. In their study, Garcia, Falkner, and Vivian (2018) state that there`s a need for further research into the effect of interactive e-learning tools on self-regulated learning. "Self-regulated learning (SRL) is the active control students take over their learning to ensure that they achieve their learning goals" (Garcia, Falkner \& Vivian, 2018, p.150). Jarret (2018) argues that there is a lack of empirical evidence on the effect of a learner's preferred learning style when learning outside the normal classroom environment. Xiao (2017) argues that there's a need for empirical research in learner-content interaction for distant learners. It is for these reasons that the learners who participated in this study were distant learners, learning in a self-paced environment. This study investigates the extent to which interactive multimedia tools assisted them in achieving their learning goals.

This study advances other studies of the same nature by using some of the recent interactive technologies like Apache Guacamole (an HTML5-based virtual desktop infrastructure software), and the Picture-in-Picture video technology which was enabled on the Google Chrome browser in 2018 (Cimpanu, 2018). The Apache Software Foundation, the developer of Apache Guacamole, first announced that they were working on this software in 2016 ("Sourceforge," 2016). Microsoft Corporation released its first HTML5-based client-less remote desktop software in 2018 ("Remote Desktop Services," 2020). The use of these features in this study is described in Appendix A.

As supported by Mayer`s theory, this study takes a learner-centered approach at identifying the optimal instructional content (Mayer, 2009). This approach evaluates the effect of the content on the learner as well as feedback from the learner regarding the content. This study aims to understand the comparative effect of interactive multimedia and text-based content when used in software application courses. It also aims to perform an exploratory study to evaluate a sample of interactive multimedia features that can be used in delivering such courses. These features include the virtual desktop infrastructure (VDI) for providing access to software applications, a toolbar-command search interface, a video with visual annotations, a dynamic interactive layout, and other features.

This study therefore addresses the following research questions

- In an e-learning-based software application course, what are self-paced learners' preferences, especially when comparing traditional text-based instructional content with interactive multimedia content, when used in training computer courses?

- Which of the two has a better effect on self-paced learners' understanding?

- For interactive multimedia, which are the most preferred features to be used in a software application course when comparing some of the recent interactive technologies?

\section{Broad Objectives of the Study}

The study aims to compare learners' comprehension as a result of using either interactive multimedia or text-based content in software application courses. It also compares learners' preferences when presented with these two content types. Furthermore, it tests features, which can be used by instructional designers to customize content suitable for a self-paced e-learning-based software application course.

\section{Specific Objectives}

The specific objectives of this study are:

- To identify learners' preferences when comparing interactive multimedia to text-based content in a self-paced, remote learning-based software application course; 
Figure 2. Conceptual framework on the effect of interactive multimedia

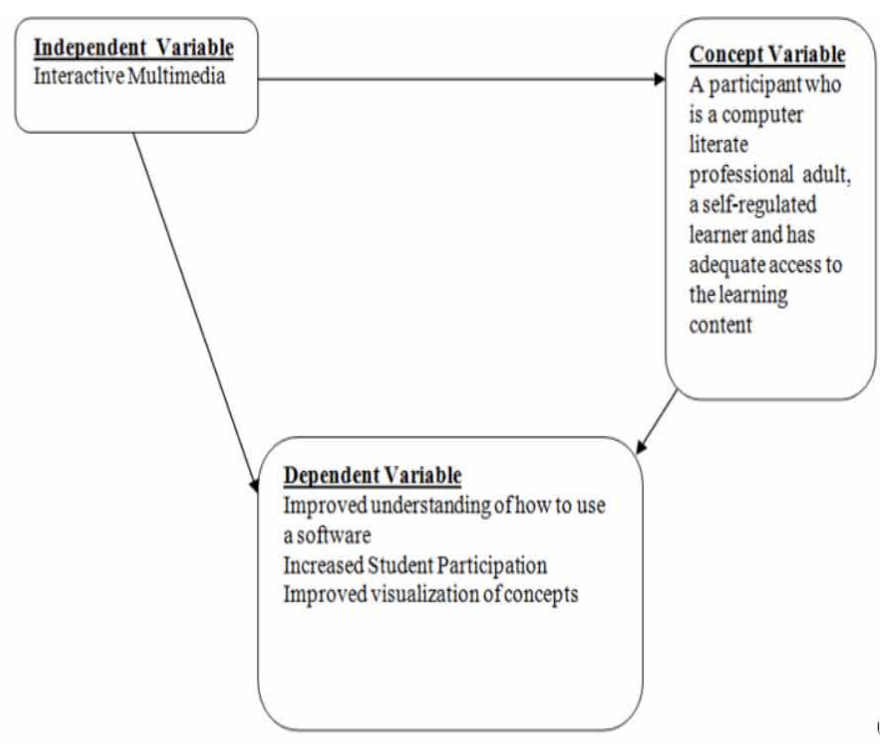

- To identify the comparative effects of interactive multimedia and text-based content on learners' comprehension in a self-paced, distance-learning based software application course; and

- To perform an exploratory study to identify the most preferable features in a self-paced, remote learning-based software application course from a sample of interactive multimedia features.

\section{Expected Results}

Based on other studies, for example by Aktas and Pektas (2011), students have shown greater interest in interactive multimedia than other forms of content. This study hypothesizes that the interactive multimedia format is more preferable than text-based content for self-paced learners taking a practical computer course.

Multimedia content enables a learner to visualize complex learning content so as to understand it (Gordon, 2013). The hypothesis in this study is that interactive multimedia format is more comprehensible than text-based content to self-paced learners taking practical computer courses. A conceptual framework on the effect of interactive multimedia is shown in Figure 2 below.

\section{LITERATURE REVIEW}

This section provides a review of studies on interactive multimedia. It also discusses the concept of interactive multimedia and its effect on learners.

\section{Animation}

Multimedia content has been shown to aid in the comprehension of abstract concepts and to promote permanency of learned knowledge (Baglama Yücesoy \& Yikmis., 2018).

Animated content significantly enhances a person's ability to learn practical skills (Rauch, Roesner, Hahnel \& Schierz, 2020). Multimedia content can be used to visualize and simplify complex content. (Gordon, 2013). This study uses interactive multimedia content to demonstrate how to use specific software. 
Interactive multimedia content contains an audio component that provides a learning option for individuals, particularly auditory learners, who prefer not to use text-based narratives (Kayalar \& Kayalar, 2017). Multimedia content can promote the user's understanding when developed with consideration for cognitive theory (Wang, Zhao, Mayer \& Wang, 2020).

However, Rosman, Mayer, \& Krampen (2016), have argued that multimedia-based content poses a greater risk on the learner because it generates a greater cognitive load. Cognitive load theory (CLT) is a theory that considers how humans process information. When learning, the information is held in working memory until it`s processed, after which it`s passed to long-term memory. The CLT theory holds that the working memory has a limited capacity therefore instructional content should avoid overloading it.

\section{Use of Interactive Multimedia}

Rachmadtullah, Zulela, and Sumantri (2019) define interactive multimedia as multiple media enabled with tools that can be controlled by the user. Studies have shown that use of interactive multimedia results in better rational thinking skills, efficient learning abilities, and greater participation by learners.

In active learning, readers actively engage in the reading process rather than passively absorbing the content. A common element between different learning theories is the emphasis that the reader`s active engagement is crucial to learning, and this is the element promoted by interactive multimedia. Interaction improves student participation and creates more interest for the learner (Aktas and Pektas, 2011).

Saputri, Rukayah, and Indriayu (2018) stated that interactive multimedia gives more space to the learner to be more active, and this, therefore, has an effect on their interest and comprehension. Lai and Chang (2020) found that interactive referencing tools assist learners to understand vocabulary and largely improves their learning. Educators should use the latest learning aids to improve the learning process (Iksan \& Saufian, 2017). For example, Divjak and Tomic (2011) note that using computer interactions for teaching mathematics contributes to a quicker realization of educational goals and fosters a more positive attitude toward learning mathematics.

Learning is not just about delivering content; interactive content and games can be used in delivering rich and meaningful content to develop higher-order thinking skills (Thomas, 2011). Deliyannis (2011) relates interactive multimedia to the activity theory model because interactive multimedia operations demonstrate the usual data processing based on a point-and-click interface that triggers underlying cognitive processes.

Encyclopedic referencing tools can be used as part of interactive multimedia. Deschênes, Goudreau, and Fernandez (2020) state that feedback mechanism and referencing tools in an interactive platform can enable learners to self-monitor their knowledge and learn new concepts. Zhang and Wu (2019) showed that learners who make use of encyclopedic referencing tools are likely to understand the learning content better than those who don't.

Virtual desktop infrastructure is one feature, which can be offered as part of interactive multimedia. This feature allows access to a software application that has been installed on a specific computer to be accessible remotely by several users. The idea behind the use of VDI in an instructional platform is guided by van de Meiji (2013); van de Meiji recommends that a software training demonstration should be followed by practice. One case where an academic institution has made use of VDI technology is the University of Massachusetts Lowell. This institution has replaced the computer laboratory with virtual desktops. Following a 66\% increase in enrollment, the institution is now able to provide its students with access to on-premise software applications, whether they are on or offcampus (Garry, 2019).

On the other hand, some researchers have identified some challenges in using interactive multimedia for learning. Essel, Osei-Poku, Tachie-Menson, and Opoku-Asare (2016) argue that learners with low computer skills or those who are not tolerant to demanding tasks do not prefer 
Interactive Multimedia. Figure 3 below shows some capabilities offered by interactive multimedia content, which can be of use to online or distant learners taking software application courses

Figure 3. Interactive multimedia capabilities that can be used in e-learning-based software application courses

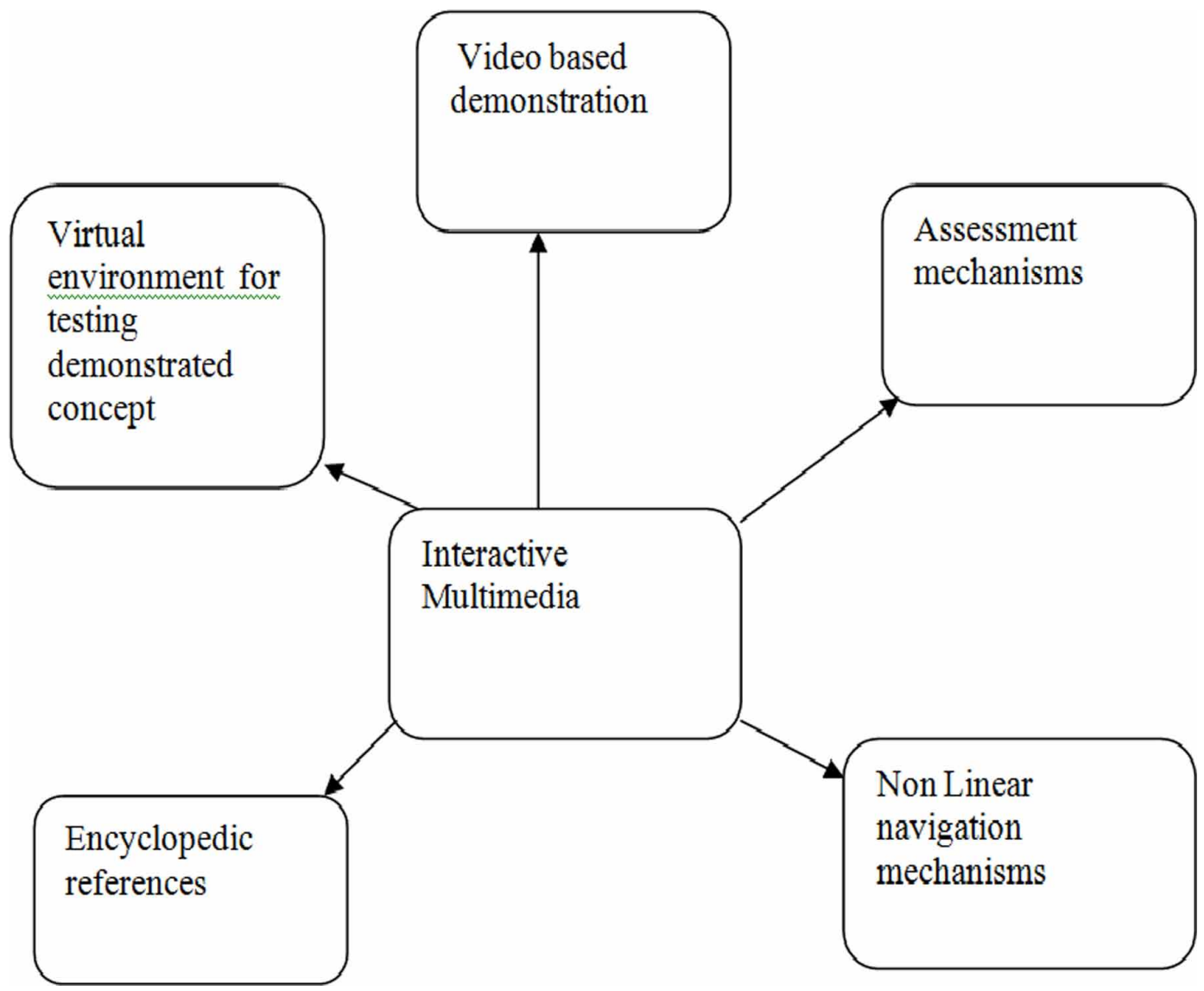

\section{METHODOLOGY}

\section{Overview}

The research was carried out over a five-month period. An experimental design resulting in qualitative data was used. The researcher conducted this study as part of the SAP training program team of the Kenya Tea Development Agency (KTDA). The Kenya Tea Development Agency is an organization that manages tea factories in Kenya. The SAP (Systems, Applications, and Products) software is an application that enables users to perform business transactions.

A baseline assessment of the learner's knowledge was initially done. The only learners who were allowed to proceed and take part in the study are the ones who showed that they had no knowledge on how to use the SAP software. The participants in this study were being trained on how to use the SAP GUI (graphical user interface) software application. The participants were first introduced to the Moodle platform and both content formats. Moodle is an open-source learning management 
system developed based on pedagogical principles, and it can be used to host and provide access to instructional content. The introductory session was conducted through the use of a recorded video. The video demonstrated how to use the Moodle platform and the content. The Moodle platform hosted both the interactive multimedia and the text-based learning content. After the introductory session, the participants were given access to the learning content. After going through a topic using either text-based or interactive multimedia-based content, the participants were subjected to a quiz where their comprehension of the content was assessed. The participants were remote, self-paced learners and were expected to use any browser-enabled device, such as a tablet or phone, to access the instructional content.

Data were captured using Moodle. These data include the scores of the participants` quiz attempts. In addition, Moodle logged the learners' usage of both content types. These data were then extracted, categorized based on the type of instruction used by the learner, and analyzed. In addition, online surveys were presented to the participant using Moodle and the responses were stored on the same platform.

Researchers have exemplified the use of web analytics in observing online users. Web analytics can assist researchers to observe users who are in remote locations performing particular activities using an online platform. McGuckin (2012) highlights the importance of web analytics as a source of empirical data. The researchers, Adraoui, Retbi, Idrissi, and Bennani (2017), evaluated learners` interaction in a Moodle-based discussion forum using a web analytics tool. Dolan, Conduit, FretheyBentham, Fahy, and Goodman (2019) evaluated the effects of web content on social media users using Facebook Insights as a data collection and measurement tool.

This section provides an overview of the interactive multimedia features. It also provides details about the participants, the research approach, and how data were collected and analyzed. Appendix 2 shows a process flow diagram that provides an overview of the activities conducted during the implementation of this study.

\section{The Interactive Multimedia Interface Layout}

The interactive multimedia content built has an event-driven software architecture based on CSS3, AJAX, video.js, HTML5 scripting, and other scripting languages. It provides a dynamic layout containing all the resources needed by the learner. This enables the user to concentrate on learning without the need to search for resources from other locations. Figure 4 below shows the object diagram of a single instance of the interactive multimedia content. The content has a responsive interface that enables the integration of components built using different technologies.

Figure 5 below shows a snapshot of the interactive multimedia interface. Different facets like the glossary and the SAP interface are expandable. The section labeled "SAP GUI Virtual App" uses the VDI technology (see Appendix 1. Figure 13). Using the VDI technology, learners made use of an SAP GUI software application installed on a separate server. The interactive multimedia features that don 't appear on the snapshot below are the swipe-able notes (see Appendix 1. Figure 12), online quizzes (see Appendix 1. Figure 14), and visual enhancements (see Appendix 1. Figure 15). The visual enhancements follow Mayer's redundancy principle, which involves highlighting important parts of the content (Mayer, 2017, p. 407). Gradable quizzes, or quizzes where the learners' responses were automatically marked, were developed using Moodle`s Cloze syntax. All quizzes provided automatic feedback to the learner. Non-gradable quizzes were developed using JavaScript and CSS3.

As shown in Figure 5 above the interactive training content was designed to have a multifaceted layout, with components that dynamically expand to be accessible. This layout enables the user to access various interfaces without navigating away from the learning content. The toolbar-command search section in Figure 5 was built using AJAX and PHP programming languages and enables the learner to search for the meaning of imagery content, e.g. toolbar commands. The table of contents in Figure 5 was built using video.js, it allows the user to jump to a particular point in the video timeline and skip portions of a video session. The video can be played using the Picture-in-picture technology 


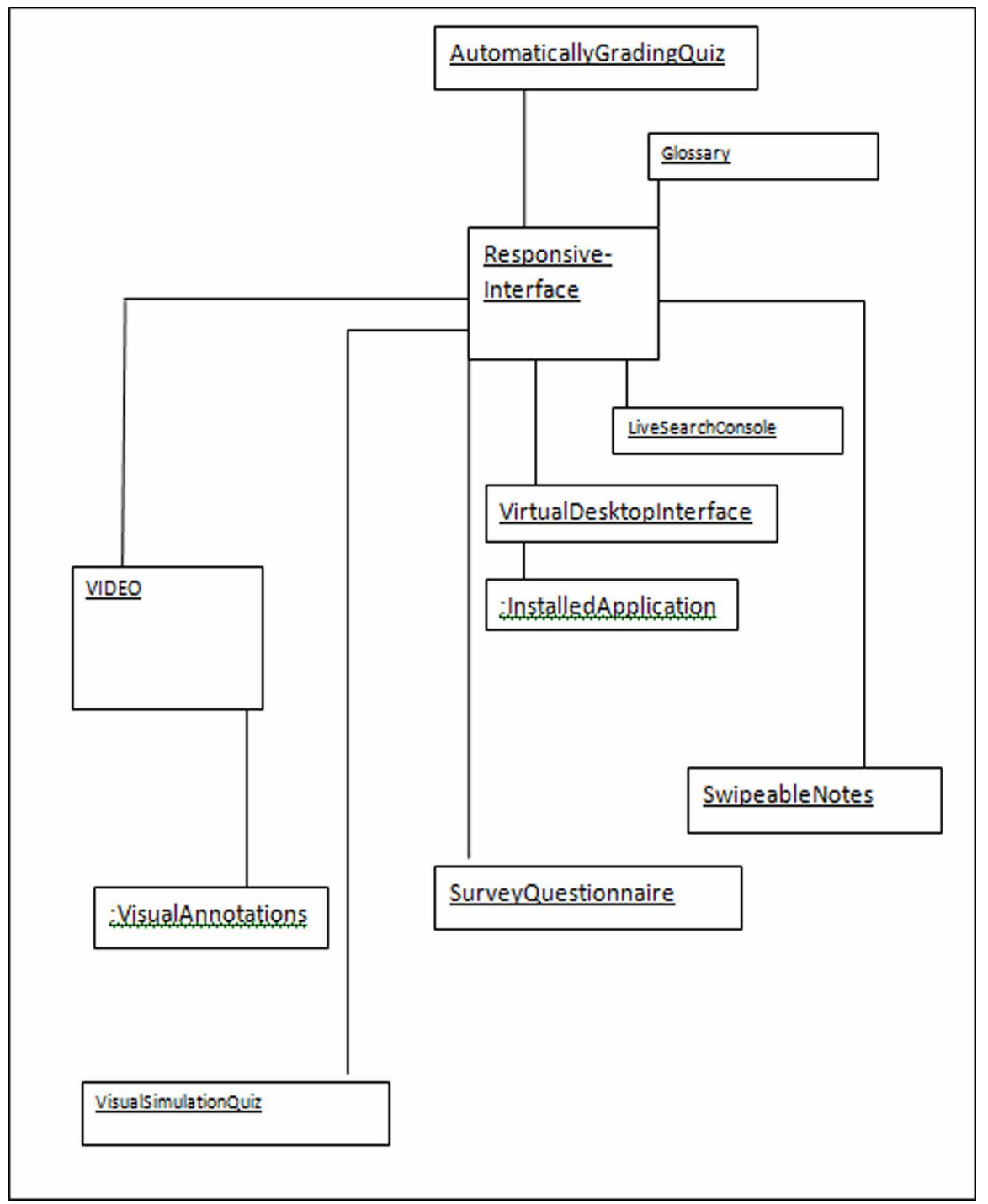

and therefore it could be viewed through a separate floating window which appeared on top of other windows. The general interface was built using I-frames, CSS3, and event-driven JavaScript architecture. Some sections like the glossary are designed to expand when the mouse moves over it to allow its content to be visible. Wikipedia suggests that framing can lower bandwidth usage, as repeating parts of a layout can be used in one frame while variable content is displayed in another. Framing can allow several pieces of information, including those from different servers, to be viewed side by side, with each section being scrollable independently ("Frame," 2020).

\section{Sampling Method and Participants}

This study tests whether the effects emerge because of the treatment to the participants. To ensure sensitivity to treatment, a priori power analysis was used to determine the minimum sample size. A Cohen's $(d)$ size of 1.67 has been recommended for studies on multimedia learning (Mayer, 2017). 
Figure 5. The interactive multimedia instructional content interface

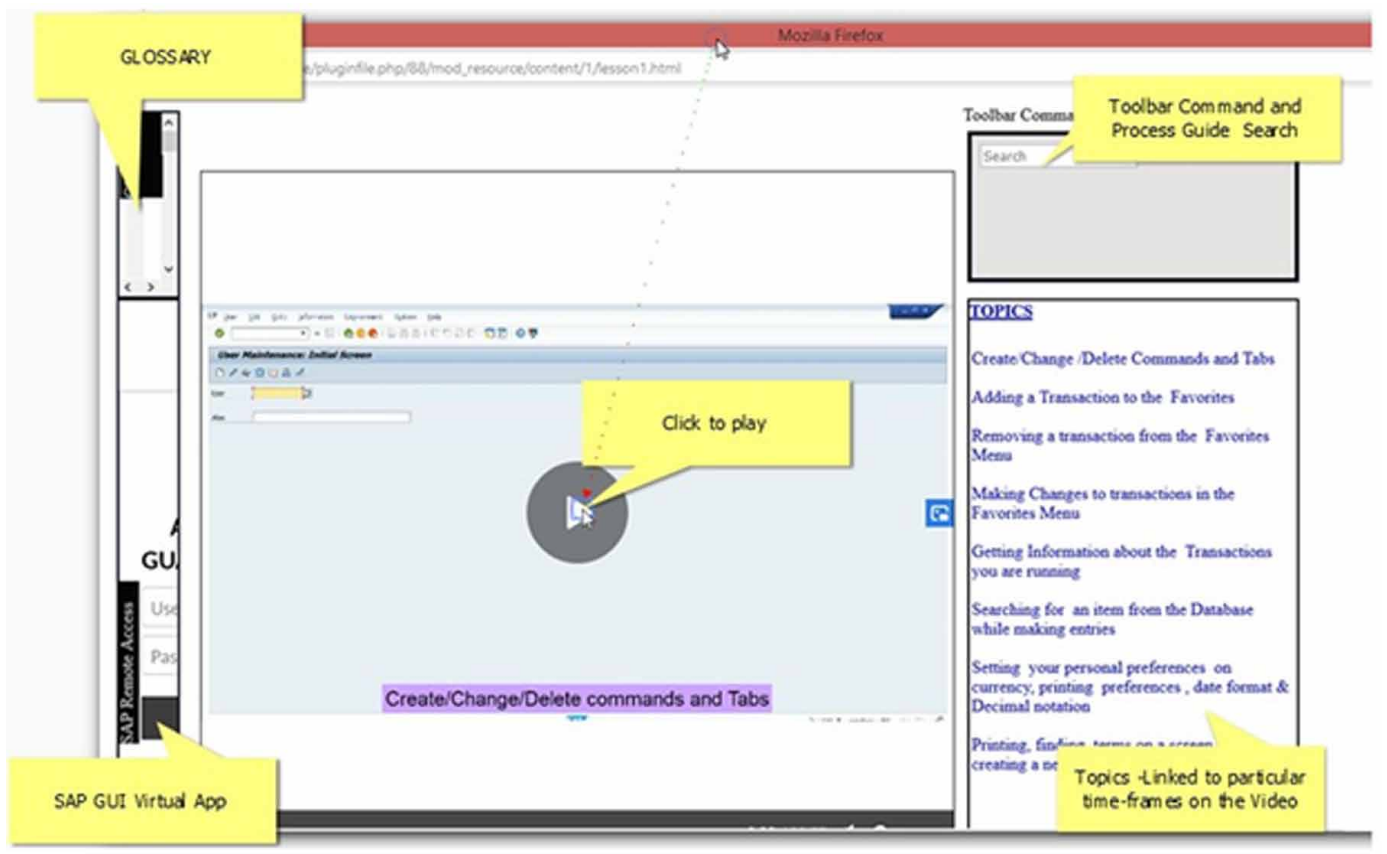

This translates into an effect size $(r)$ of 0.64 . These parameters produce a calculated sample size of 18 , after using an effect size(r) of 0.64 , an error probability of 0.05 and a t-test value of 1 .

Despite the Priori power calculation showing that a sample of 18 would be enough for the study, a total of 111 participants were evaluated in this study. Ibrahem and Alamro (2020), who conducted a study of a similar nature, had a sample size of 80 participants. Panev and Preradovic (2020), who conducted a study of a similar nature, had a sample size of 52 students. Afify (2018), who also tested the effect of multimedia content on learners, used a sample size of 36 participants

One hundred and eleven participants took part in this study. They were between the ages of 21 and 55; they were all computer-literate. Seventy-eight learners were university degree holders, thirtythree of them did not have a University degree but had attained a diploma. Ninety-three participants were male and eighteen were female. They included factory production staff, plant maintenance staff, procurement staff, clerks, and technicians.

\section{Data Collection and Preparation}

Quantitative data were collected from the participants. These include the students' performance on the quizzes, utilization of both text-based and interactive multimedia content, and the online survey responses.

\section{The Online Survey}

To prepare the survey questions a pretest was conducted using a printed questionnaire. The questions were pre-tested twice, and they included five open-ended and five closed-ended questions. They were administered to 10 learners who had tested both the interactive multimedia and text-based content. These 10 learners were drawn from this study`s participants.

The final online survey was presented to the participants through Moodle. It had two questions. One question was regarding their preference for either interactive multimedia or text-based content. The other was a question regarding their preferred interactive multimedia features. The responses 
to the online surveys were stored and analyzed on Moodle. This information could be retrieved by accessing the Moodle usage report. Eighty participants responded to the online survey.

\section{Content-type Preference Data}

To identify the learners ' preference for either text-based content or interactive-multimedia based content the learners were evaluated in two ways. First, the learners were asked for their preferred content through the online survey. Moodle stored their responses and provided an analyzed report. Secondly, the Moodle LMS tracked the learner`s activity, and thereafter an activity evaluation was conducted. The first evaluation enabled the researcher to determine the content that the learners were

Figure 6. Screenshot of Moodle's activity report

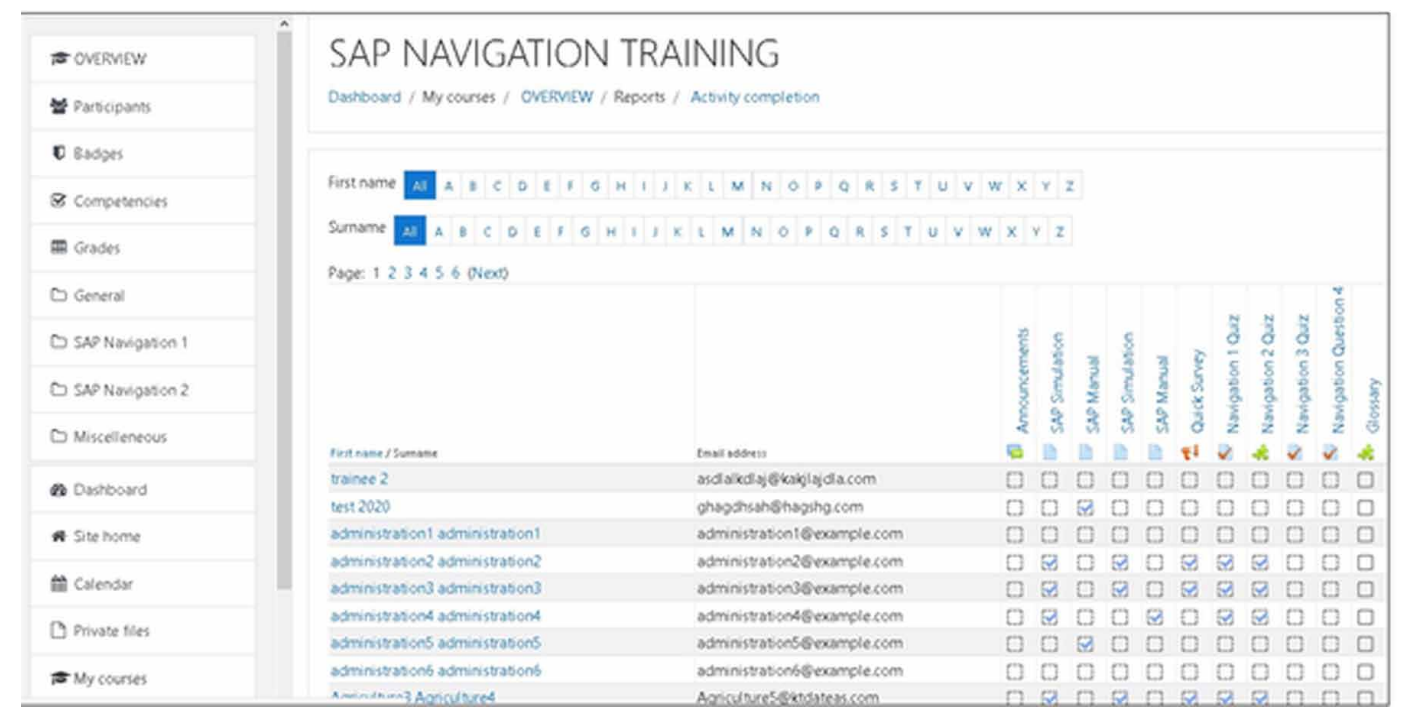

interested in. The reason for the second evaluation was to evaluate the behavior of the learners after having viewed the content. The participants in this study had been taken through an introductory session and therefore they were aware of both the interactive multimedia and the text-based content before they engaged with the Moodle platform.

For the learners`activity evaluation, Moodle tracked the learners`activity and generated a report called the activity completion report. This report contained activity data for all participants who took part in this study. This report provided an overview of how the user engaged with the instructional content on the Moodle platform. A screenshot of the report as it appears in the Moodle system is shown in Figure 6 below. The report was extracted in Microsoft Excel format. Analysis of this report resulted in a comparison of the learners` preference rate for each type of content.

\section{Performance Data}

For comprehension rate, the users were evaluated based on their performance in online quizzes that appeared in each topic. The scores were stored on Moodle and were categorized by topic. The researcher then correlated the learner's score for a given topic with the content type that the learner used to receive instruction on that topic. A $t$-test was also performed to test the significance of the difference in the initial results. 
The grade reports, which were extracted from Moodle contained scores for the 48 participants who were able to take the quizzes. It should be noted that these questions, which had been developed using the Cloze syntax, could be automatically graded by the Moodle platform. Statistical tools in Microsoft Excel were used to merge the activity completion and grade reports and generate a report showing the performance of each user based on the type of training content that he or she utilized for a given topic. Using the resulting report, it was possible to obtain the average scores for all learners based on their use of each content type. These scores helped the researcher deduce the effect of the respective content type on comprehension.

\section{Data Analysis and Results}

This section provides analytical information based on the research objectives. The learners were evaluated in three ways

1. Comprehension analysis

2. Content-type preference analysis

3. Feature preference analysis

Figure 7. Learners` average performance based on the content used

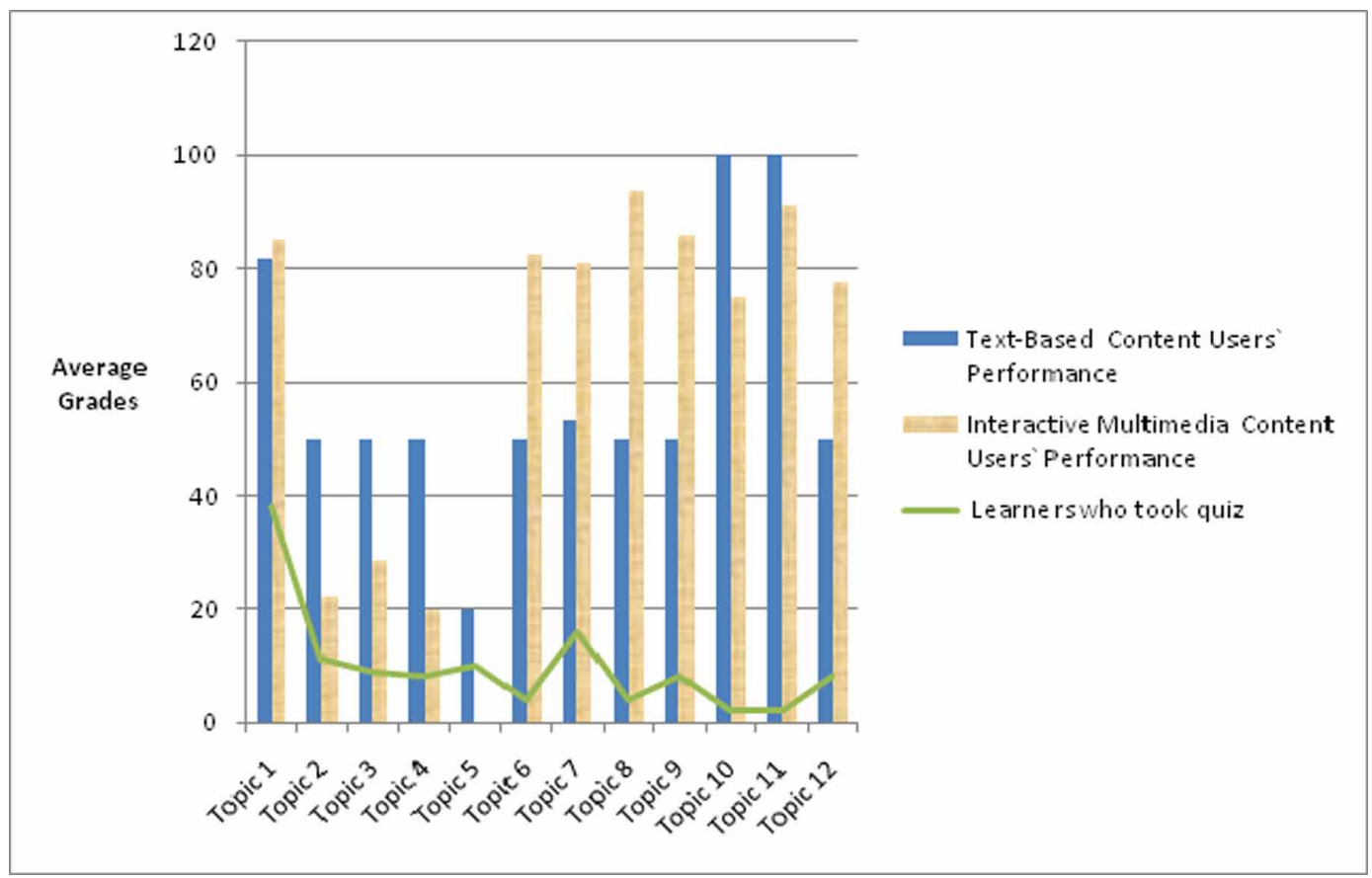

The above-mentioned experiments had varying sample sizes because of different reasons. For example, there are cases where some participants used the learning content but did not take the assessment test. In such a case the learner was evaluated based on his or her preference rate but not based on the comprehension rate. Likewise, learners who made use of the learning content but failed to respond to the survey would be evaluated based on their content preference rate but not based on their feature preference rate. 
Figure 8. Comparison of the overall quiz performance based on the instructional content type

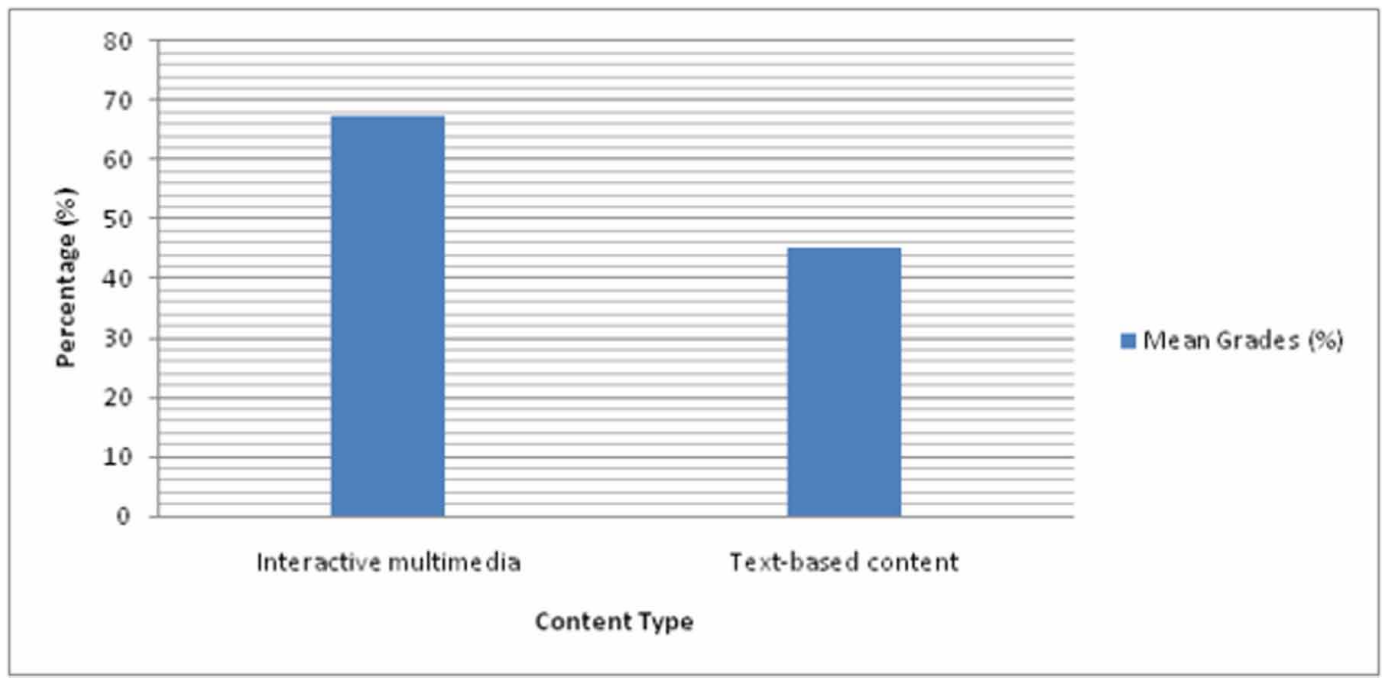

\section{Comprehension Rate Analysis}

This study sought to find out the comparative effect of Interactive Multimedia and text-based content on the learners` understanding. The learners took an assessment test after going through the learning content. Figure 7 below shows the learners` average performance based on the content type that they used. The learners` score in each topic is out of 100 percent.

The researcher ensured that all quizzes had the same difficulty level and that they were based on content that was available in their related topics (i.e., in both interactive multimedia and text-based

Table 1. A two-sample t-test of performance results based on the content used

\begin{tabular}{|c|c|c|}
\hline & $\begin{array}{c}\text { Interactive multimedia } \\
\text { content }\end{array}$ & Text-based content \\
\hline Mean performance for all learners & 67.23777 & 45.21645 \\
\hline Variance & 1335.577 & 2157.682 \\
\hline Observations & 37 & 22 \\
\hline \multicolumn{3}{|c|}{$t$-test results } \\
\hline Degrees of freedom (df) & 36 & \\
\hline$t$-statistic & 1.901125 & \\
\hline$P(T \leq t)$, one-tailed & 0.032657 & \\
\hline$t$-critical, one-tailed & 1.688298 & \\
\hline
\end{tabular}

format). As shown in Figure 7, in some topics, the use of text-based content was correlated with better performance. However, for most learners, the use of interactive multimedia was correlated with better performance. Figure 8 below shows the average performance for all learners based on 
Table 2. Comparison of learners' preferences based on the online survey

\begin{tabular}{|l|l|l|l|}
\hline & \multicolumn{1}{|c|}{$\begin{array}{c}\text { Preference for } \\
\text { Multimedia content }\end{array}$} & $\begin{array}{c}\text { Considers interactive multimedia } \\
\text { content to be the same as text- } \\
\text { based content }\end{array}$ & $\begin{array}{c}\text { Considers multimedia content } \\
\text { to be worse than text-based } \\
\text { content }\end{array}$ \\
\hline Percentage & 66.25 & 32.5 & 1.25 \\
\hline $\begin{array}{l}\text { Number of } \\
\text { Respondents }\end{array}$ & 56 & 23 & 1 \\
\hline
\end{tabular}

the content type used. The overall average score for learners who used interactive multimedia was $67 \%$, and those who used text-based content had an average score of $45 \%$.

To test the statistical difference in the above data, a two-sample $t$-test was conducted. The results are shown in Table 1. The significance test was a one-tailed $t$-test, for varying observations, and a significance level of 0.05 was used. The $t$-test results indicate that there's a statistical difference in the overall learners` performance, where $p<0.05$ and $t$-critical $<t$-statistic. Each observation

Figure 9. Learners' activity data based on the content type used

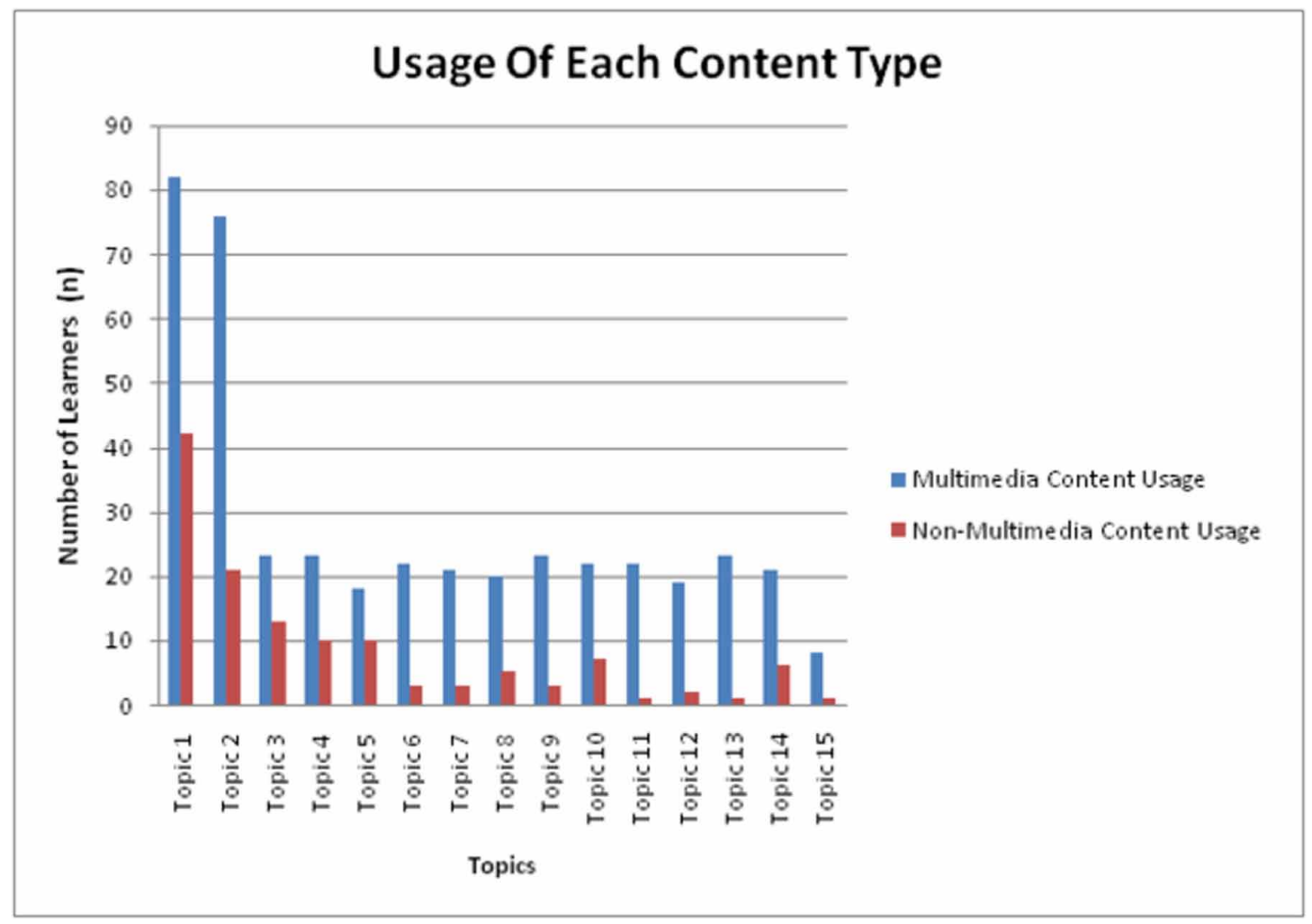

identified in Table 1 represents a learner`s average performance in all quizzes. These quizzes are either correlated to the use of interactive multimedia or text-based content. The results of the significance test confirm that the performance of learners who use interactive multimedia content is better than those who use text-based content. 


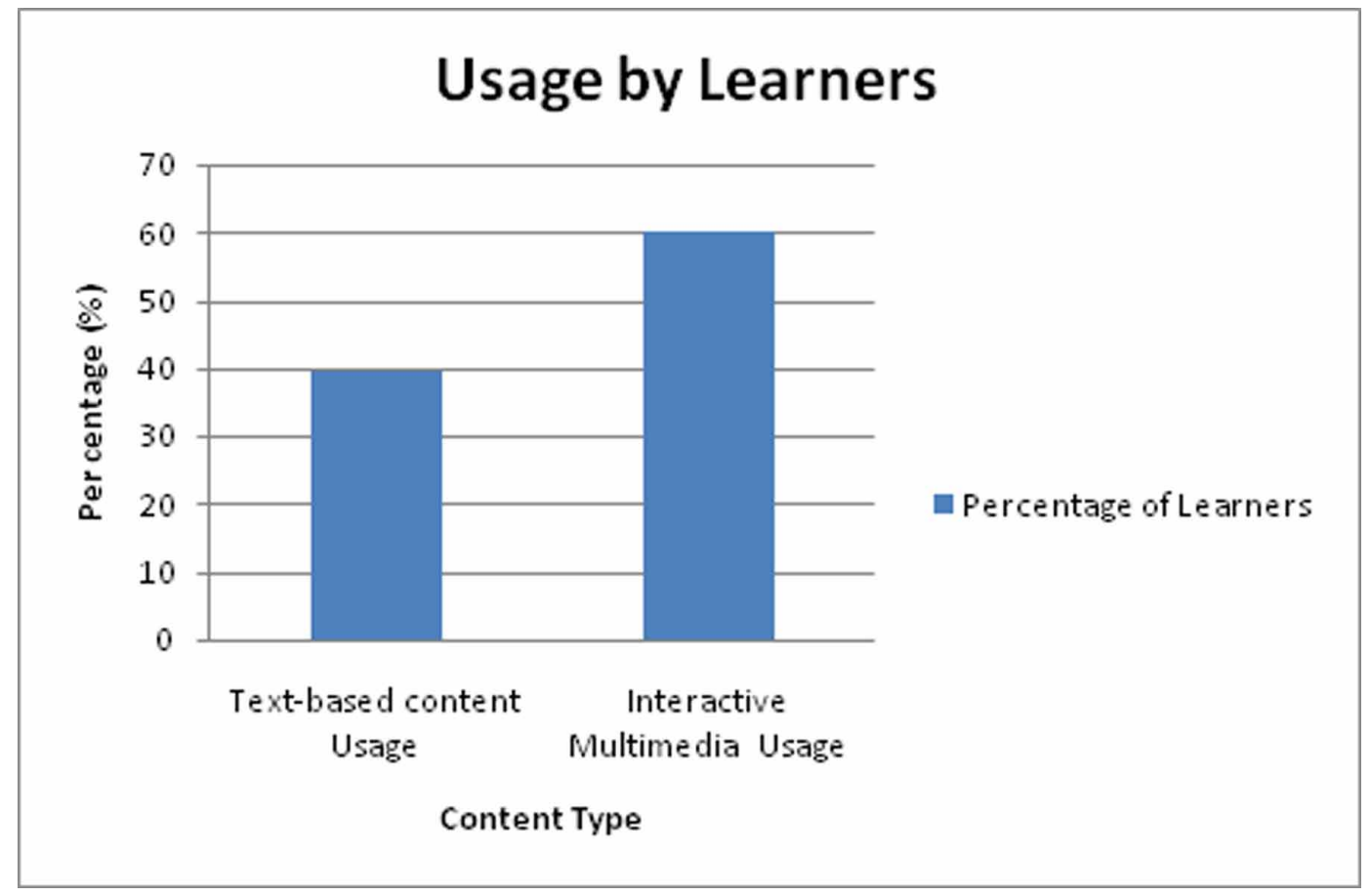

Table 3. Two-sample t-test for the activity completion data

\begin{tabular}{|l|r|r|}
\hline & Text-based content Usage & Interactive Multimedia Content Usage \\
\hline Mean usage for all learners & 2.101694915 & 3.188118812 \\
\hline Variance & 4.265341905 & 11.69425743 \\
\hline Observations & 59 & 101 \\
\hline \multicolumn{3}{|c|}{$t$-test results } \\
\hline Degrees of freedom (df) & 2.505125868 & \\
\hline$t$-statistic & 0.006627151 & \\
\hline$P(T \leq t)$, one-tailed & 1.654554876 & \\
\hline$t$-critical, one-tailed & 0.05 & \\
\hline Significance level & \multicolumn{3}{|c|}{} \\
\hline
\end{tabular}

\section{Content-type Preference Rate Analysis}

This study sought to identify the learners preferences when comparing interactive multimedia to text-based content in a self-paced, remote learning-based software application course. Table 2 below shows the learners' responses regarding their preferences when comparing interactive multimedia and text-based content. As seen from the table, most learners responded that they prefer interactive multimedia-based content.

In addition, the learners` preference was investigated by evaluating their activity on the Moodle platform. The following chart shows an analysis of the learners`activity data. It shows the number of 
Table 4. Comparison of learners' preferences based on the online survey

\begin{tabular}{|l|r|r|}
\hline \multicolumn{3}{|c|}{ Responses on Features } \\
\hline & Number of Responses & Preference Rate (\%) \\
\hline Video presentation & 75 & 33 \\
\hline Access to the SAP GUI (VDI) & 64 & 29 \\
\hline Access to the reference material & 62 & 28 \\
\hline Swipe-able notes & 23 & 10 \\
\hline Total & 224 & 100 \\
\hline
\end{tabular}

times learners made use of a specific type of content in each topic. Figure 9 shows that in all topics, learners preferred to use interactive multimedia content rather than text-based content.

To test the statistical difference in the completion rate of each content type, a two-sample $t$-test was performed. The results are shown below in Table 3. The significance test was one-tailed for varying

Figure 11. The preference rate for the different interactive multimedia features

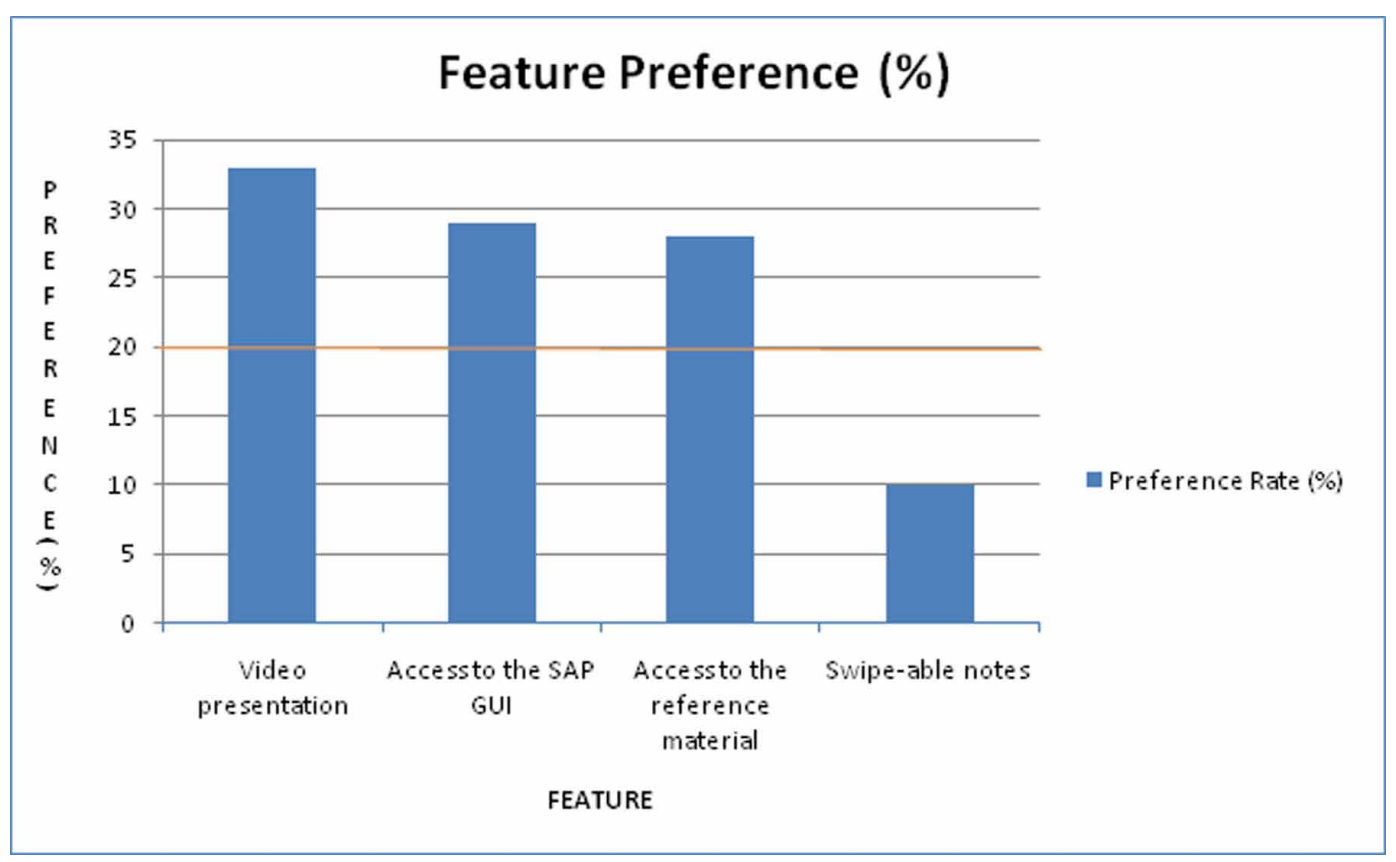

observations, and a significance level of 0.05 was used. The results suggest a statistical difference in the data from Figure 10 above, where $p<0.05$ and $t$-statistic $>\mathrm{t}$-critical. Hence, there is a significant difference between the learners` preference for interactive multimedia to text-based content.

\section{Feature Preference Responses}

The research includes an exploratory study whose aim is to identify the most preferable features in a self-paced, remote learning-based software application course from a sample of interactive multimedia 
features. This data was collected using an online survey. In the online survey, users were asked to identify at least three of their most preferred features in the interactive multimedia content. Eighty participants responded to the survey. The results are shown in Table 4. The most preferred feature is the video presentation, whereas the least preferred feature is the swipe-able notes.

Figure 11 below shows the learners` preference for specific interactive multimedia features based on the responses of the online survey. The cut-off line separates the three most preferred features from the rest of the features. The participants had been requested to select three of their most preferred features. The three most preferred features are the video, access to the reference material, and the VDI.

\section{DISCUSSION AND CONCLUSION}

\section{Discussion}

The initial results of the activity completion report show that the activity completion rate for the interactive content was $60.27 \%$ and that for the text-based content was $39.73 \%$. The activity completion rate was used as a metric to measure the learners' utilization of the two types of content. The results show that these learners, who had initially encountered both content types through the introductory video, prefer the interactive multimedia to the text-based content. This concurs with the fact that, in the online survey, most learners responded that they preferred interactive multimedia-based content to text-based content. As shown in Table 3, the difference in the $t$-test results is statistically significant.

Some researchers who conducted a similar study reported that most participants expressed interest in multimedia content, but the statistical test results did not show a significant difference. One example is a study by Daly, Bulloch, Ma and Aidulis (2016), which evaluates the effect of multimedia against static content based on two subject areas: pharmacology and physiology. When interviewed, most of the students in the study preferred multimedia content, but the actual test results did not show a statistical difference. Therefore, the statistical significance in the learners` preference for interactive multimedia may not exist in all cases and would vary based on the subject that the learners are undertaking.

An evaluation of the learners' performance based on the content type used in each topic was conducted. The results reveal that most learners who used interactive multimedia content scored higher than those who used text-based content. The results suggest that learners who use interactive multimedia-based content to learn software applications can understand the content much better than those who use text-based content. A $t$-test further shows that the difference, as shown in Table 1, is statistically significant.

The outcome in a study conducted by Jena and Chakraborty (2018) was that improved interest in the learning content does not result in improved learning. Researchers who have investigated the effect of interactive multimedia on learning have drawn different conclusions (Afify, 2018). One difference in these studies is the subject that the learners were taking. This study provides empirical evidence on the effect of interactive multimedia for a learner taking a computer applications course. The results support existing theories that multimedia content has a positive impact on comprehension in e-learning (Baglama et al., 2018). The results support existing theories that relate the use of interactive content to improved student participation, (Akbas and Pektas, 2011).

Mayer's theory is that interactive multimedia improves the learning process by providing consistent feedback mechanisms as well as multiple representations of content (Mayer, 2009). This capability was delivered in this study through the provision of the swipe-able notes along with the video presentation, and through quizzes with automatic feedback mechanisms and other features. The effect of interaction has also been shown in the outcome of a previous study where students who used an interactive platform performed better than those who used textbooks to study patient cases for diagnoses in urology (Schneider, Albers, \& Müller-Mattheis, 2015). 
Researchers have shown that there's limited multimedia-learning research on working adults (Mutlu-Bayraktar, Cosgun, and Altan, 2019; Pastore, Briskin, and Asino, 2016). Researchers like Garcia, Falkner, and Vivian (2018) have called on researchers to investigate the effect of new interactive technologies on self-paced learners. Jarret (2018) argues that there is a lack of empirical evidence on the effect of a learner's preferred learning style when learning outside the normal classroom environment. This investigation is conducted on self-paced learners, as part of in-service training. This study also responds to calls for further research into learner-content interaction for distant learners (Xiao, 2017).

As highlighted by Ibrahem and Alamro (2020) not all features of interactive content are preferable for use in a software course. This study provides insights on how recent interactive technologies, like the HTML5 based VDI and a video with video.js based enhancements, influence the learner's interest in the content. The results of the online survey show that most learners identified the video presentation as the most important feature in the interactive multimedia interface. The second most popular feature in the interactive multimedia interface was access to the SAP GUI, which was enabled using the VDI technology. The third most popular feature was the glossary and other reference features, and the least popular one was the swipe-able notes. The results suggest that the video presentation and the VDI are integral features in interactive multimedia for use in software application courses. According to Rauch, Roesner, Hahnel \& Schierz (2020), video presentations have a tremendous effect on learners who are learning practical skills. This study also introduces empirical evidence from the learners' perspective on the effect of these new technologies. One of these technologies is the HTML5-based VDI. This technology is important due to its ability to allow the learner to practice. The idea behind the use of VDI in an instructional platform is guided by Van de Meiji (2013), Van de Meiji recommends that a software training demonstration should be followed by practice As this is an exploratory study, future studies should evaluate whether there is a statistical difference in learners' preferences for different interactive features.

The idea behind collecting the learners' feedback and evaluating the effect of the content on the learners' preference was based on a learner-centered approach to enhancing learning outcomes and motivation (Mayer, 2009). These results would enable educators who provide e-learning-based software application courses to develop content that improves participation as well as the learning outcomes. One challenge in developing interactive multimedia is that its development is considerably more time-consuming than text-based content.

The KTDA tea factories comprise of staff who don 't interact with computers in their day-to-day activity for example mechanics, drivers, and plant technicians. The VDI capability coupled with the video demonstration allowed the above-mentioned factory workers to practice how to use the software while also making reference to the multimedia presentation.

This research was conducted at a period when parts of Kenya had been isolated so as to control the spread of the coronavirus disease and "social distancing" measures had outlawed classroom learning. Online interactive multimedia was vital in that it substituted an instructor-led course and therefore the above-mentioned measures, which were put in place to reduce the spread of the coronavirus disease, did not interrupt learning. Regardless of these challenges, the time taken to roll out the SAP software to the factories during this phase was shorter than during the previous phase. During one of the SAP project meetings, it was noted that this turnaround time was partly attributable to the interactive multimedia content that we had provided for learning on how to use the SAP software

\section{CONCLUSION}

This study aimed to identify learners' comprehension rate when using either interactive multimedia or text-based content in practical computer courses. The study also compared the learners' preferences for each type of content. The results reveal a statistical difference in the comprehension rate between students using interactive multimedia content and those using text-based content. Therefore, the study concludes that learners who use interactive multimedia content have a better comprehension 
rate than those who use text-based content when learning to use software. The study also concludes that use of interactive multimedia leads to higher participation than text-based content for self-paced software application courses. While other studies have tested learners' preference for these content types in other subject areas, this study provides new empirical data on preferences specific to software application courses and for self-regulated, in-service adult learners.

An exploratory study, testing the learners' preferences for specific interactive multimedia features, was also conducted. The findings indicate that, from the features provided, learners were more interested in the video presentation and the VDI than the referencing tools or the swipe-able notes. The study suggests that instructional content designers and educators should consider using these interactive multimedia features when developing content for computer courses. While a statistical test of significance was not conducted for the users' responses on their preferred interactive multimedia features, the survey results suggest a need for further research on these features. The study suggests that a video presentation with video.js enhancements and an HTML5 based VDI has a greater impact on the software learners` motivation than referencing tools or swipe-able notes.

The results of this study will aid instructional content designers and educators in designing content meant for practical computer courses. It provides research-based information on some features required in instructional content for software application courses, with emphasis on interactive multimedia content. The study shows that interactive multimedia spurs the learners` interest in the content and results in improved learning.

\section{Future Considerations}

As seen in the recent global events, e-learning will continue to play a critical role in learning. Researchers should test the effect of interactive multimedia using other technologies such as threedimensional animation and immersive technologies like virtual reality. More research also needs to be conducted on the effect of different interactive features on comprehension. These investigations should include statistical tests of significance 


\section{REFERENCES}

Adraoui, M., Retbi, A., Idrissi, M. K., \& Bennani, S. (2017). Social learning analytics to describe the learners' interaction in online discussion forum in Moodle. In 2017 16th International Conference on Information Technology Based Higher Education and Training (ITHET) (pp. 1-6). IEEE.

Afify, M. K. (2018). The Effect of the Difference Between Infographic Designing Types (Static vs Animated) on Developing Visual Learning Designing Skills and Recognition of its Elements and Principles. International Journal of Emerging Technologies, 13(9), 1. doi:10.3991/ijet.v13i09.8541

Akbas, O., \& Pektaş, H. (2011). The effects of using an interactive whiteboard on the academic achievement of university students. Asia-Pacific Forum on Science Learning and Teaching, 12.

Apache Guacamole / News. (2016, December 31). In Sourceforge. https://sourceforge.net/p/guacamole/ news/2016/05/guacamole-is-now-apache-guacamole-incubating/

Baglama, B., Yücesoy, Y., \& Yıkmış, A. (2018). Using Animation as a Means of Enhancing Learning of Individuals with Special Needs. TEM Journal, 7, 670-677. doi:10.18421/TEM73-26

Cimpanu, C. (2018, October 22). Google Chrome Picture-in-Picture support is now live for desktop users. ZDNet. https://www.zdnet.com/article/google-chrome-picture-in-picture-support-is-now-live-for-desktop-users/

Clark, R. C., \& Mayer, R. E. (2008). E-learning and the science of instruction: Proven guidelines for consumers and designers of multimedia learning (2nd ed.). Pfeiffer.

Coward, F. L., Crooks, S. M., Flores, R., \& Dao, D. (2012). Examining the effect of gender and presentation mode on learning from a multimedia presentation. Multidisciplinary Journal of Gender Studies, 1, 48-69. doi:10.4471/generos.2012.03

Daly, C., Bulloch, J., Ma, M., \& Aidulis, D. (2016). A Comparison Of Animated Versus Static Images In An Instructional Multimedia Presentation. Advances in Physiology Education, 40(2), 201-205. doi:10.1152/ advan.00053.2015 PMID:27105738

Deliyannis, I. (2012). Interactive multimedia. BoD - Books on Demand. doi:10.5772/2394

Deliyannis, I. (2019). Introductory chapter: Convergence of content and technology - The role of interaction. The Future of Television - Convergence of Content and Technology. 10.5772/intechopen.83742

Divjak, B., \& Tomić, D. (2011). The impact of game-based learning on the achievement of learning goals and motivation for learning mathematics - Literature review. Journal of Information and Organizational Sciences, $35,15-30$.

Dolan, R., Conduit, J., Frethey-Bentham, C., Fahy, J., \& Goodman, S. (2019). Social media engagement behavior. European Journal of Marketing, 53(10), 2213-2243. doi:10.1108/EJM-03-2017-0182

Essel, H. B., Osei-Poku, P., Tachie-Menson, A., \& Opoku-Asare, N. A. (2016). Self-Paced Interactive Multimedia Courseware: A Learning Support Resource for Enhancing Electronic Theses and Dissertations Development. Journal of Education and Practice, 7(12), 74-84.

Frame (World Wide Web). (2020, November 6). Wikipedia, the free encyclopedia. Retrieved December 15, 2020, from https://en.wikipedia.org/wiki/Frame_(World_Wide_Web)

Garcia, R., Falkner, K., \& Vivian, R. (2018). Systematic literature review: Self-Regulated Learning strategies using e-learning tools for Computer Science. Computers \& Education, 123, 150-163. doi:10.1016/j. compedu.2018.05.006

Garry, A. (2019, September 12). Virtual desktop infrastructure providing powerful and cost-effective solutions for universities. Technology Solutions That Drive Education. https://edtechmagazine.com/higher/article/2019/09/ universities-embrace-virtual-desktop-infrastructure-serve-students

Gordon, D. (2013, November 25). Storyboarding in Education. Retrieved August 15, 2020 from https://www. slideshare.net/DamianGordon1/storyboarding-in-education

Hassan, H. G. (2016). Designing Infographics to support teaching complex science subject: A comparison between static and animated Infographics (Doctoral dissertation). Iowa State University. 
Ibrahem, U., \& Alamro, A. (2020). Effects of Infographics on Developing Computer Knowledge, Skills and Achievement Motivation among Hail University Students. International Journal of Instruction, 14(1), 907-926. doi:10.29333/iji.2021.14154a

Iksan, Z. H., \& Saufian, S. M. (2017). Mobile Learning: Innovation In Teaching And Learning Using Telegram. IJPTE: International Journal of Pedagogy and Teacher Education, 1(1). Advance online publication. doi:10.20961/ijpte.v1i1.5120

Jarrett, C. (2018, April 12). Students did not benefit from studying according to their supposed learning style. Phys.Org. https://phys.org/news/2018-04-students-benefit-learningstyle.html

Jena, A. K., \& Chakraborty, S. (2018). Epistemological Beliefs: Its Relationship with Learning Styles, Learning Approaches, and Achievement. Asia Pacific Journal of Education, Arts and Sciences, 5(1), 60-70. https://files. eric.ed.gov/fulltext/ED585389.pdf

Kayalar, F., \& Kayalar, F. (2017). The effects of Auditory Learning Strategy on Learning Skills of Language Learners (Students' Views). IOSR Journal of Humanities and Social Science, 22. . 10.9790/0837-2210070410

Lai, S. L., \& Chang, J. S. (2020). Toward a pattern-based referencing tool: Learner interactions and perceptions. ReCALL, 32(3), 272-290. doi:10.1017/S0958344020000105

Lee, L., Chao, Y., Huang, C., Fang, J., Wang, S., Chuang, C., Kang, C., Hsin, L., Lin, W., Fang, T., \& Li, H. (2017). Cognitive style and mobile E-learning in emergent otorhinolaryngology-head and neck surgery disorders for millennial undergraduate medical students: Randomized controlled trial. Journal of Medical Internet Research, 20(2), e56. doi:10.2196/jmir.8987 PMID:29439943

Mayer, R. (2009). Multimedia Learning (2nd ed.). Cambridge University Press. doi:10.1017/CBO9780511811678

Mayer, R. (2017). Using multimedia for E-Learning. Journal of Computer Assisted Learning, 33(5), $403-423$. doi:10.1111/jcal.12197

McGuckin, C., \& Crowley, N. (2012). Using Google analytics to evaluate the impact of the CyberTraining project. Cyberpsychology, Behavior, and Social Networking, 15(11), 625-629. doi:10.1089/cyber.2011.0460 PMID:23075266

Mutlu-Bayraktar, D., Cosgun, V., \& Altan, T. (2019). Cognitive load in multimedia learning environments: A systematic review. Computers \& Education, 141, 103618. doi:10.1016/j.compedu.2019.103618

Panev, I., \& Mikelic, P., Nives, \& Lauc, T. (2020). Investigating interactivity in instructional video tutorials for an undergraduate informatics course. Issues in Educational Research, 30, 203-223.

Pastore, R., Briskin, J., \& Asino, T. I. (2016). The multimedia principle: A meta-analysis on the multimedia principle in computer-based training. International Journal of Instructional Technology and Distance Learning, 13(11), 17-29. https://www.learntechlib.org/p/177384/

Peters, D. (2013). Interface design for learning: Design strategies for learning experiences. Pearson Education.

Rachmadtullah, R., Zulela, M. S., \& Sumantri, M. S. (2019). Computer-based interactive multimedia: A study on the effectiveness of integrative thematic learning in elementary schools. Journal of Physics: Conference Series, 1175(1), 012028. doi:10.1088/1742-6596/1175/1/012028

Rauch, A., Jahn, F., Roesner, A., Hahnel, S., \& Schierz, O. (2020). Impact of the DC/TMD instructional video on the practical skills of undergraduate students-A single-blinded, randomized controlled trial. European Journal of Dental Education. Advance online publication. doi:10.1111/eje.12618 PMID:33053252

Remote Desktop Services. (2020, December 2). In Wikipedia. https://en.wikipedia.org/wiki/Remote_Desktop_ Services\#Remote_Desktop_HTML5_Web_Client

Rosman, T., Mayer, A. K., \& Krampen, G. (2016). A longitudinal study of information seeking knowledge in psychology undergraduates: Exploring the role of information literacy instruction and working memory capacity. Computers \& Education, 96, 94-10. doi:10.1016/j.compedu.2016.02.011

Saputri, D. Y., Rukayah, R., \& Indriayu, M. (2018). Need assessment of interactive multimedia based on game in elementary school: A challenge into learning in 21st century. International Journal of Educational Research Review, 3(3), 1-8. doi:10.24331/ijere.411329 
Schneider, A., Albers, P., \& Muller-Mattheis, V. (2015). E-learning in urology: Implementation of the learning and teaching platform CASUS - Do virtual patients lead to improved learning outcomes? A randomized study among students. Urologia Internationalis, 94(4), 412-418. doi:10.1159/000368653 PMID:25871786

Shiu, A., Chow, J., \& Watson, J. (2019). The effectiveness of animated video and written text resources for learning microeconomics: A laboratory experiment. Education and Information Technologies, 25(3), 1999-2022. doi:10.1007/s10639-019-10025-1

SticeE.SticeJ.AlbrechtC. (2015). Study Choices by Introductory Accounting Students: Those Who Choose to Study by Reading Text Outperform Those Who Choose to Study by Watching Video Lectures. Available at SSRN 2787478. 10.2139/ssrn.2787478

Taub, T. (2019, February 27). Integration of interactive multimedia courses and their impact on the teacher's role and status. Prizmah: Center for Jewish Day Schools. https://prizmah.org/integration-interactive-multimediacourses-and-their-impact-teacher\%E2\%80\%99s-role-and-status

Thomas, D. (2011). A New Culture of Learning: Cultivating the Imagination for a World of Constant Change. Createspace Independent Publishing Platform.

Wang, F., Zhao, T., Mayer, R. E., \& Wang, Y. (2020). Guiding the learner's cognitive processing of a narrated animation. Learning and Instruction, 69, 101357. doi:10.1016/j.learninstruc.2020.101357

Werbach, K. (2016). Flip flop: The realities of blended teaching. https://medium.com/@kwerb/flip-flop-therealities-of-blended-teaching-cdecbec $628 \mathrm{c} 5$

Zhang, D., \& Wu, J. G. (2019, September). Learning across contexts: a multiple case study of mobile dictionary in Chinese EFL learners' incidental and intentional vocabulary learning. In World Conference on Mobile and Contextual Learning (pp. 4-11). Academic Press. 


\section{APPENDIX 1 - FEATURES OF THE INTERACTIVE MULTIMEDIA CONTENT IN THIS STUDY}

\section{Swipe-able Notes}

To advance through the swipe-able notes, the user would swipe the screen. The notes disappear when the user selects play to resume the video.

Figure 12. Swipe-able notes (overlaps with the video when it is paused)

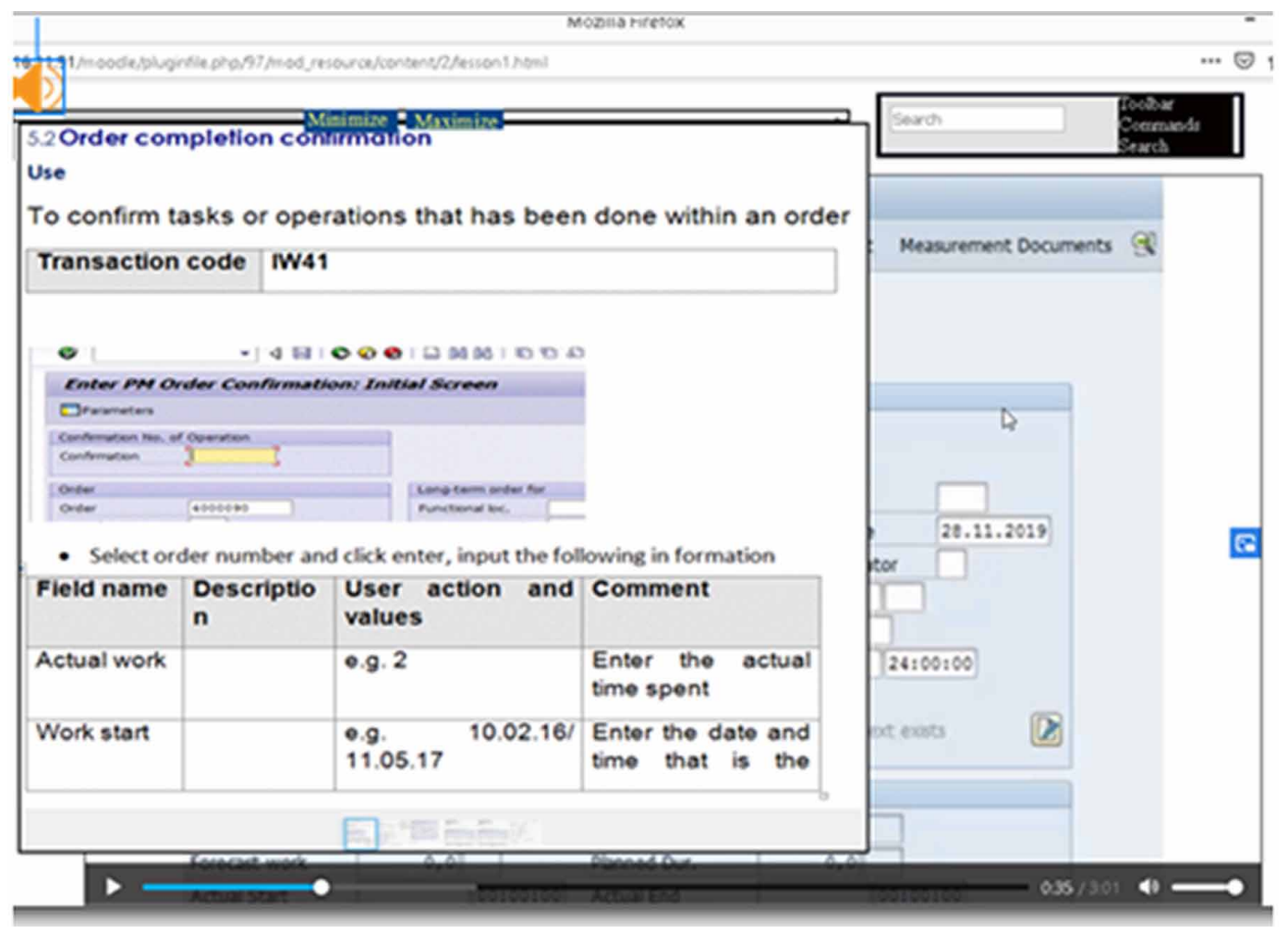




\section{The Virtual Desktop Infrastructure}

Figure 13. Web-based access to a native SAP GUI that is not a web-based application

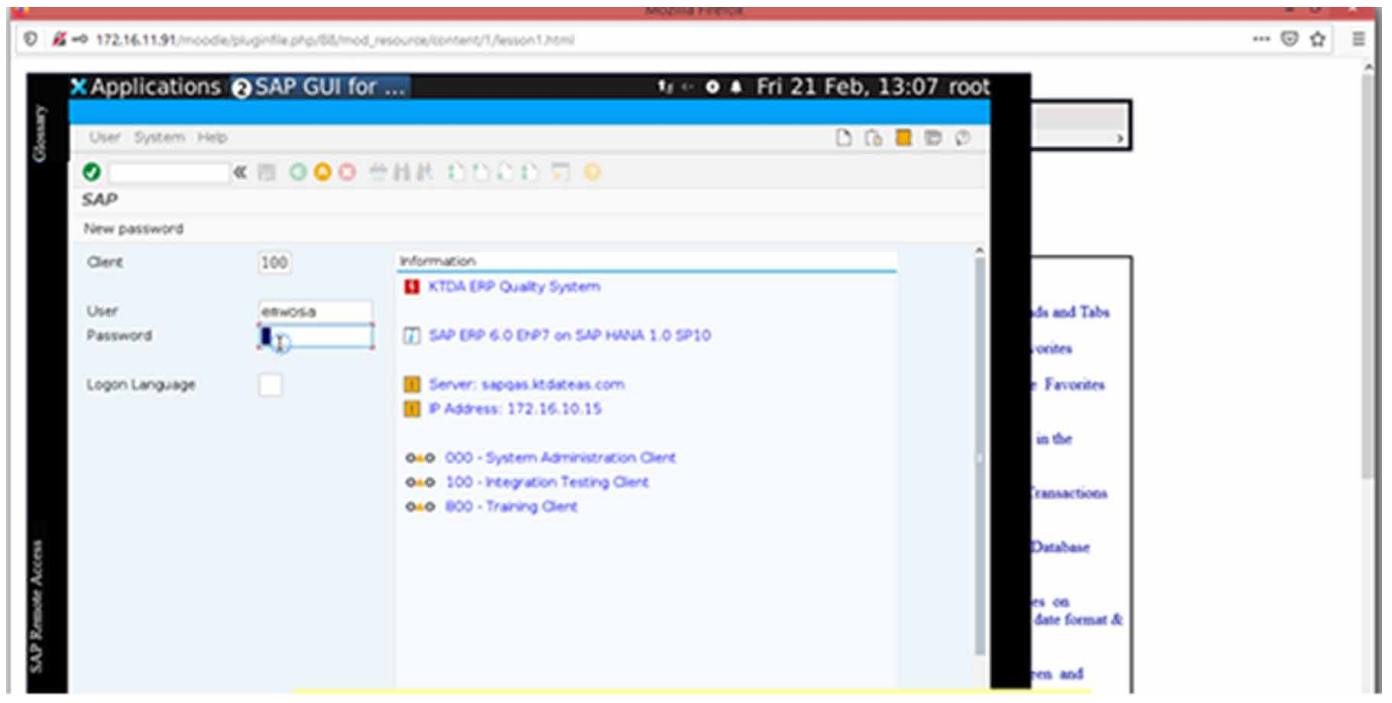

\section{The Quizzes}

Figure 14. Gradable questions with automatic feedback

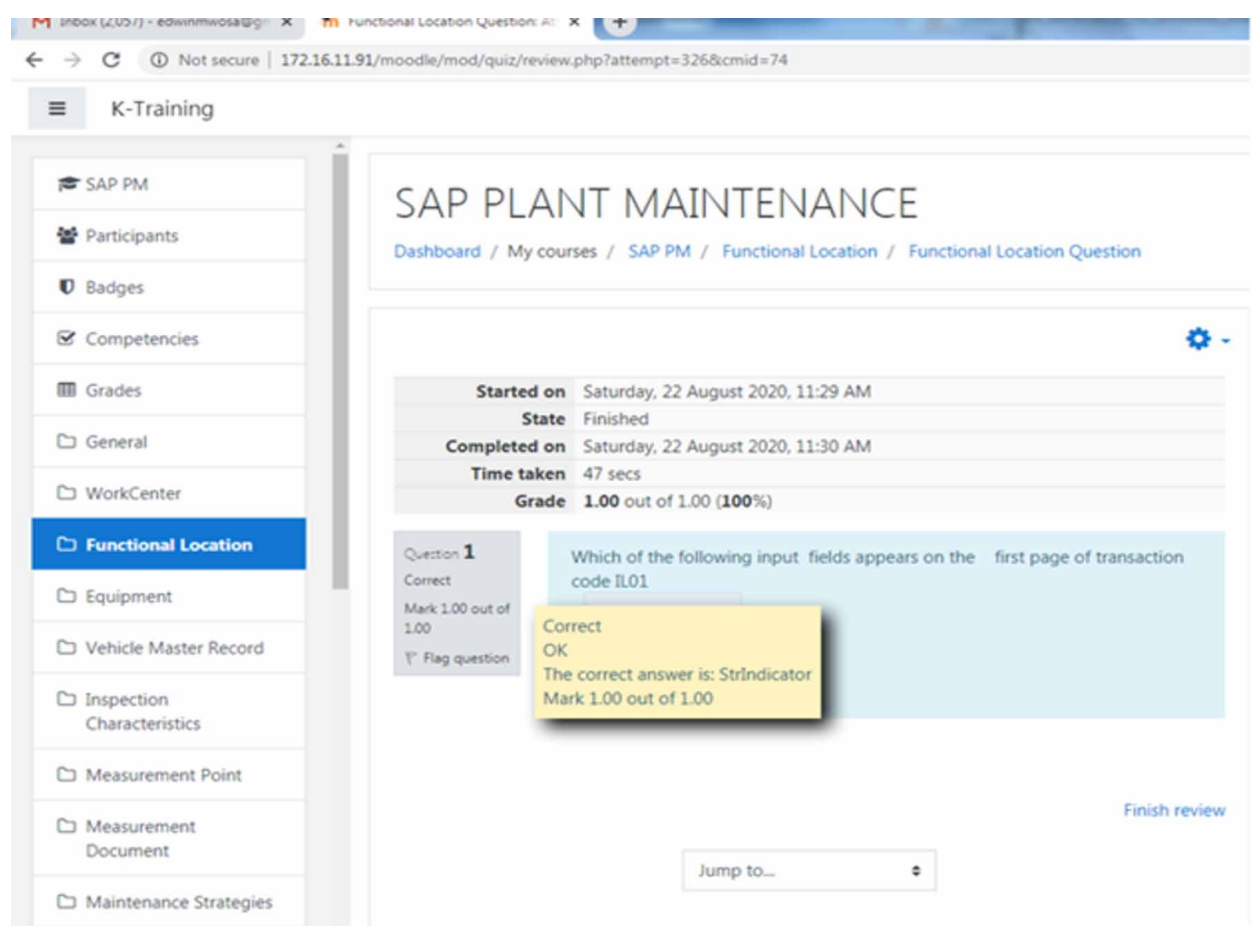




\section{Visual Effects}

Figure 15. A video`s visual enhancement - the spotlight effect

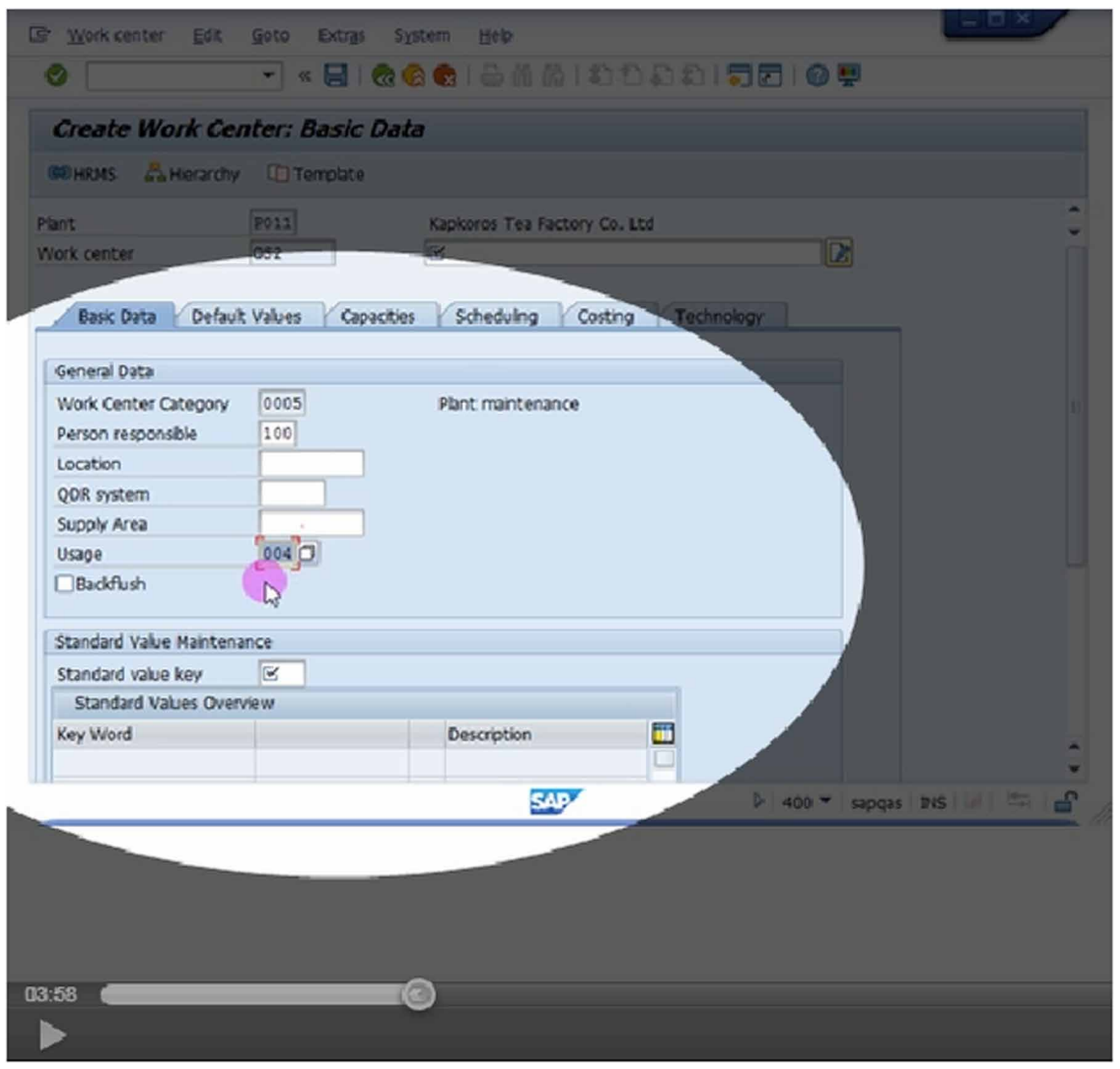




\section{APPENDIX 2 - THE STUDY PROCESS}

Figure 16 shows a process flow chart of the activities, from the initial engagement with KTDA's management up to the drafting of the final report.

Figure 16. Process flow diagram of activities

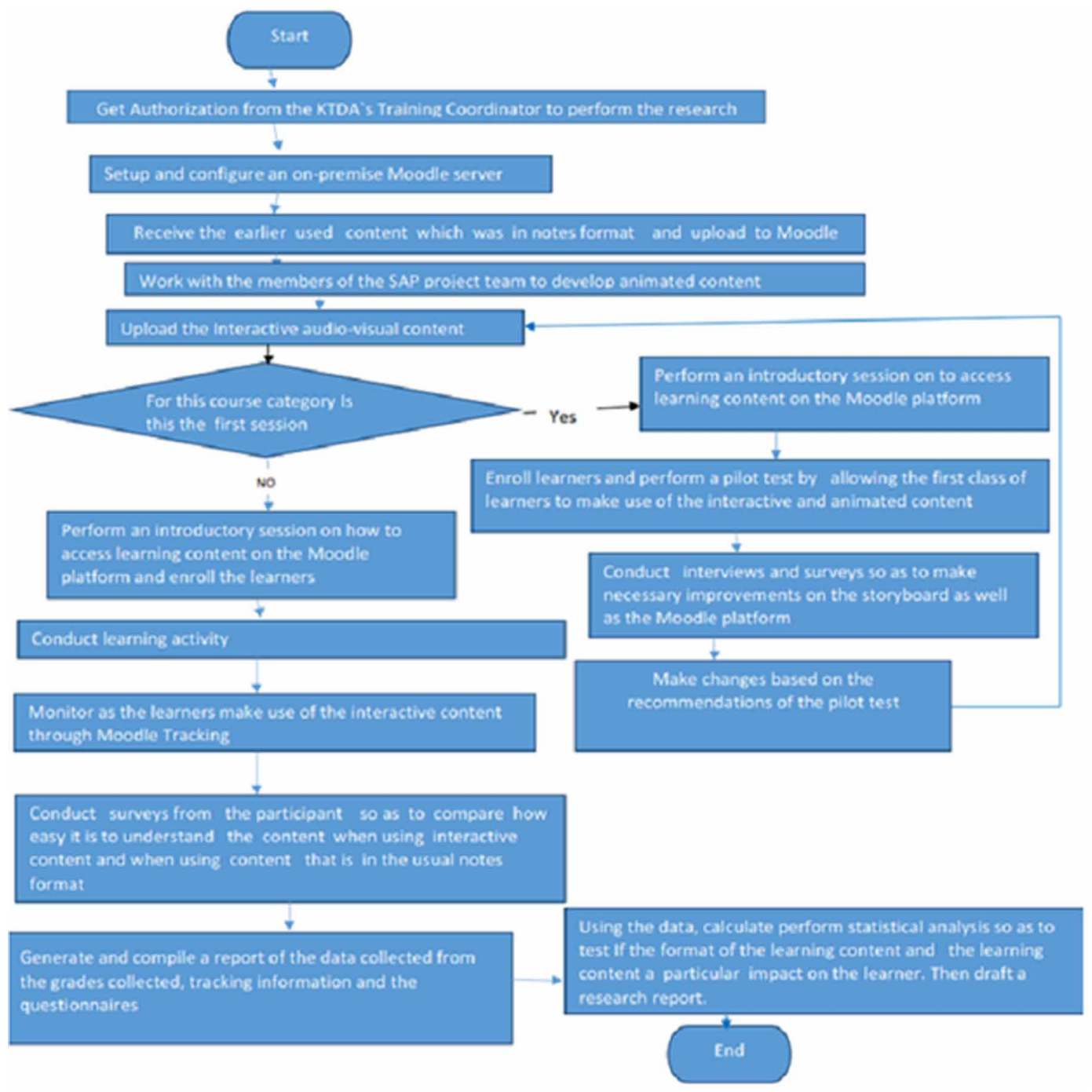

Edwin Mwosa received an Honours degree from University of South Africa in 2014. He has held various position in education mainly in training computer courses. His first interaction with e-learning was in 2004 where he used the Skillsoft e-learning platform to train computer courses. He is also the author of the article An Evaluation Of The Impact Of Keyword Frequency On Keyword Prominence. 